\title{
UPAYA PENINGKATAN KINERJA GURU MELALUI TEKNIK LESSON STUDY SECARA KOLABORATIF DAN RUTIN DI SD NEGERI 2 PENGANTEN KECAMATAN KLAMBU KABUPATEN GROBOGAN SEMESTER II TAHUN $2017 / 2018$
}

\author{
Suliyono \\ SD Negeri 2 Penganten Kecamatan Klambu, Grobogan
}

\begin{abstract}
The purpose of this study is to determine the extent of the teacher's perspective on learning media as a tool to facilitate the achievement of learning objectives in the State Elementary School Bancaran 4 Bangkalan district. This research type is descriptive research. Many teachers in Bangkalan district do not understand that the media is a learning tool to facilitate the achievement of learning objectives. This is evident from the results of data analysis that shows not consider the media as something that is important to achieve learning objectives. Teachers also rarely use learning media because it is still the process of choosing to adjust the learning materials and create a simple media that takes a little time, learning media is very important to support the process of learning activities, and the number of media in elementary schools is not too much.
\end{abstract}

Keywords: lesson study, action research

\begin{abstract}
ABSTRAK
Tujuan penelitian ini adalah untuk meningkatkan kinerja guru melalui teknik lesson study secara kolaboratif dan rutin di SD Negeri 2 Penganten Kecamatan Klambu Kabupaten Grobogan Semester II Tahun 2017/2018. Penelitian ini dilakukan selama semester II tahun pelajaran 2017/2018 dari penyusunan Proposal bulan Januari sampai penulisan laporan hasil penelitian pada bulan Maret 2018. Subyek penelitian adalah 8 Guru di SD Negeri 2 Penganten Kecamatan Klambu Kabupaten Grobogan. Kondisi awal persentase kinerja hanya 38,375\%. Metode yang digunakan dalam penelitian ini adalah metode Penelitian Tindakan Sekolah. Setiap siklus terdiridariempat tahap yaitu tahap perencanaan (planning),pelaksanaan tindakan(acting),pengamatan (observing)dan refleksi(reflecting).Analisa data yang digunakan dalam penelitian ini menggunakan analisis deskriptifnkomparatif yaitu dengan membandingkan nilai hasil tes awal,siklus pertama dan siklus ke dua. Dari analisa data yang dilaksanakan dalam penelitian ini diperoleh simpulan peningkatan kinerja guru secara keseluruhan adalah dari awal sebesar 38,375\% (kategori rendah), setelah tindakan siklus I menjadi 60\% (kategori sedang), dan setelah tindakan siklus II meningkat lagi menjadi 84,583\% (kategori sangat tinggi)
\end{abstract}

Kata Kunci: lesson study, PTK

Korespondensi : Suliyono. SD Negeri 2 Penganten Kecamatan Klambu, Grobogan Email :--- 
PENDAHULUAN

Salah satu persoalan pendidikan yang sedang dihadapi bangsa kita adalah persoalan mutu pendidikan pada setiap jenjang dan satuan pendidikan. Berbagai usaha telah dilakukan untuk meningkatkan mutu pendidikan nasional, antara lain melalui berbagai pelatihan dan peningkatan kompetensi guru, pengadaan buku dan alat pelajaran, perbaikan sarana dan prasarana pendidikan, dan meningkatkan mutu manajemen sekolah. Namun demikian, indikator mutu pendidikan belum menunjukkan peningkatan yang berarti. Sebagian sekolah, terutama di kota-kota, menunjukkan peningkatan mutu pendidikan yang cukup menggembirakan, sebagian besar lainnya masih memprihatinkan.

Dalam upaya meningkatkan mutu pendidikan nasional, pemerintah khususnya melalui Departemen Pendidikan Nasional terus menerus berupaya melakukan berbagai perubahan dan pembaharuan sistem pendidikan kita. Salah satu upaya yang sudah dan sedang dilakukan, yaitu berkaitan dengan faktor guru. Lahirnya Undang-Undang No. 14 tahun 2005 tentang Guru dan Dosen dan Peraturan Pemerintah No. 19 Tahun 2005 tentang Standar Nasional Pendidikan, pada dasarnya merupakan kebijakan pemerintah yang di dalamnya memuat usaha pemerintah untuk menata dan memperbaiki mutu guru di Indonesia. Michael G. Fullan yang dikutip oleh Suyanto dan Djihad Hisyam (2000) mengemukakan bahwa "educational change depends on what teachers do and think...". Pendapat tersebut mengisyaratkan bahwa perubahan dan pembaharuan sistem pendidikan sangat bergantung pada "what teachers do and think", atau dengan kata lain bergantung pada penguasaan kompetensi guru.

Jika kita amati lebih jauh tentang realita kompetensi guru saat ini agaknya masih beragam. Sudarwan Danim (2002) mengungkapkan bahwa salah satu ciri krisis pendidikan di Indonesia adalah guru belum mampu menunjukkan kinerja (work performance) yang memadai. Hal ini menunjukkan bahwa kinerja guru belum sepenuhnya ditopang oleh derajat penguasaan kompetensi yang memadai, oleh karena itu perlu adanya upaya yang komprehensif guna meningkatkan kompetensi guru.

Berdasarkan masalah di atas, maka berbagai pihak mempertanyakan apa yang salah dalam penyelenggaraan pendidikan kita? Kurangnya pemahaman guru akan tugasnya sebagai agen pembelajaran, 
merupakan salah satu faktor rendahnya mutu pembelajaran. Guru sebagai agen pembelajaran harus memiliki beberapa kompetensi diantaranya adalah kompetensi kepribadian, kompetensi pedagogik, kompetensi profesional, dan kompetensi sosial. Apabila guru mampu menguasai kompetensi tersebut maka mutu pendidikan akan meningkat.

Dari uraian di atas, penulis selaku kepala sekolah melakukan terobosan untuk menyikapi sekaligus memperbaiki pola-pola pemikiran yang salah dengan memberikan pengarahan/ pembinaan guru berbasis sekolah yang dinamakan dengan (Lesson Study) secara kolaboratif dan berkelanjutan berlandaskan prinsipprinsip kolegalitas dan mutual learning untuk membangun komunitas belajar, untuk membekali guru dalam melaksanakan tugasnya sebagai agen pembelajaran.

Maka berdasarkan latar belakang tersebut penulis melakukan upaya perbaikan untuk meningkatkan mutu pembelajaran di Negeri 2 Penganten Kecamatan Klambu Kabupaten Grobogan melalui Penelitian Tindakan Sekolah (PTS) dengan tujuan untuk mendeskripsikan Upaya Peningkatan Kinerja Guru Melalui Teknik Lesson Study Secara Kolaboratif dan Rutin di SD
Negeri 2 Penganten Semester II Tahun $2017 / 2018$

Lesson Study merupakan model pembinaan profesi pendidik melalui pengkajian pembelajaran secara kolaboratif dan berkelanjutan berlandaskan prinsip-prinsip kolegalitas dan mutual learning untuk membangun komunitas belajar.

Lesson Study adalah program yang diterapkan oleh SISTTEMS, (Strengthening In-Service Teacher Training of Mathematics and Science Education at Junior Secondary Level) yaitu bentuk kerjasama antara JICA (Japan International Cooperation Agency) dan MONE / Depdiknas (Ministry of National Education / Departemen Pendidikan Nasional) Indonesia.

Lesson Study bukan merupakan metoda atau strategi pembelajaran tetapi kegiatan yang dapat menerapkan berbagai metoda dan strategi pembelajaran yang sesuai dengan situasi, kondisi, kemampuan komunitas pembelajaran serta berbagai permasalahan yang dihadapi dalam kegiatan pembelajaran.

Lesson Study adalah metode yang berorientasi pada praktek untuk meningkatkan keterampilan mengajar oleh guru-guru itu sendiri. 


\section{Teknik Lesson Study}

Lesson Study biasanya terdiri dari tahapan-tahapan berikut:

a. Guru mempersiapkan rencana pembelajaran

(PLAN-tahap perencanaan),

b. Salah seorang guru mempraktekkan rencana pembelajaran di kelas yang sesungguhnya, sedangkan para guru pendamping yang lain dan kepala sekolah mengamati pembelajaran tersebut (DO-tahap pembelajaran terbuka),

c. Setelah pembelajaran, guru pengajar dan para guru pengamat mendiskusikan hasil pembelajaran, kemudian disampaikan kepada kepala sekolah untuk menyampaikan umpan balik pada guru pengajar.

Kelebihan dari metode ini adalah, peran guru yang dapat berubah-ubah: siapapun dapat berperan sebagai guru pengajar dalam satu waktu dan menjadi guru pengamat dilain waktu. Pergantian peran ini menciptakan rasa saling mengerti serta mendukung diantara guru dan secara efektif meningkatkan mutu proses belajar-mengajar. Bermacammacam istilah yang digunakan untuk metode sejenis ini diberbagai sumber pustaka, misalnya: "action research", "coaching", dan "clinical supervision". Dalam program ini, Lesson Study akan digunakan sebagai istilah umum untuk kegiatan yang berusaha untuk mengembangkan profesi guru.

Revolusi pembelajaran yang dilakukan melalui kegiatan Lesson Study telah menunjukkan hasil yang luar biasa. Indikator keberhasilannya itu dapat dilihat diantaranya:

a. Tumbuhnya semangat guru dalam mencari dan menerapkan berbagai metoda atau strategi pembelajaran. Hal ini dikarenakan setiap dilaksanakan implementasi Lesson Study, guru dituntut untuk memilih metoda atau strategi pembelajaran yang lain dari yang pernah dipakai dalam implementasi- implementasi sebelumnya.

b. Tumbuhnya prinsip kolegalitas diantara guru-guru mata pelajaran, khususnya yang sejenis. Hal ini ditunjukkan dengan semakin efektifnya kegiatan Musyawarah Guru Mata Pelajaran (MGMP). Sebelumnya, kegiatan MGMP itu, kalaupun ada, hanya terbatas bila menghadapi ujian nasional saja. Bahkan kegiatan MGMP pun biasanya diselenggarakan oleh sub rayon, bahkan rayon, yang tentu secara 
domisili kesulitan dijangkau oleh transportasi, terutama di sekolahsekolah yang berada di pinggiran. Melalui kegiatan MOMP yang diselenggarakan di Base Camp, lebih mudah dijangkau oleh guru-guru anggota MOMP, sehingga silaturrahmi dan kolegalitas, sebagai ruh Lesson Study, dapat tercipta.

c. Dukungan moril dan materil dari pimpinan sekolah semakin kuat. Hal ini bisa dilihat pada setiap kegiatan Lesson Study melalui MGMP mendapat dukungan dari kepala sekolah. Bahkan hampir setiap kegiatan Lesson Study dihadiri langsung oleh kepala sekolah-kepala sekolah, khususnya dalam satu base camp. Tentunya, dengan dukungan yang besar dari pimpinan akan memberi motivasi bagi untuk mengikuti kegiatan MGMP. Tetapi sebaliknya, bila pimpinan sekolah tidak memberi motivasi, maka gurunya pun tidak akan semangat mengikuti kegiatan MGMP.

d. Guru mendapat banyak pencerahan, selain dari teman sejawat, juga dari para dosen pembimbing (fasilitator) yang setiap pertemuan selalu hadir untuk memberikan dukungan, baik ketika melakukan PLAN (perencanaan),

(pelaksanaan/implementasi) dan SEE (refleksi).

Oleh karena itu, upaya untuk meningkatkan kegiatan Lesson Study agar berjalan lebih baik harus mendapat perhatian dan merupakan tugas dan tanggung jawab bersama, baik bagi guruguru, kepala sekolah, dinas pendidikan dan Lembaga Pendidikan Tenaga Kependidikan (LPTK) yang terlibat langsung dengan kegiatan Lesson Study.

\section{Tahapan Lesson Study}

Lalu bagaimana kiatnya agar Lesson Study yang kita lakukan efektif? Berkenaan dengan tahapan-tahapan dalam Lesson Study ini, dijumpai beberapa pendapat. Menurut Wikipedia (2007) bahwa Lesson Study dilakukan melalui empat tahapan dengan menggunakan konsep Plan-Do-Check-Act (PDCA).

Sementara itu, Slamet Mulyana (2007) mengemukakan tiga tahapan dalam Lesson Study, yaitu: (1) Perencanaan (Plan); (2) Pelaksanaan (Do) dan (3) Refleksi (See). Sedangkan Bill Cerbin dan Bryan Kopp dan University of Wisconsin mengetengahkan enam tahapan dalam Lesson Study, yaitu:

a. Form a Team: membentuk tim sebanyak 3-6 orang yang terdiri guru yang bersangkutan dan pihak-pihak 
lain yang kompeten serta memilki kepentingan dengan Lesson Study.

b. Develop Student Learning Goals: anggota tim mendiskusikan apa yang akan dibelajarkan kepada siswa sebagai hasil dari Lesson Study.

c. Plan the Research Lesson: guru-guru mendesain pembelajaran guna mencapai tujuan belajar dan mengantisipasi bagaimana para siswa akan merespons.

d. Gather Evidence of Student Learning: salah seorang guru tim melaksanakan pembelajaran, sementara yang lainnya melakukan pengamatan, mengumpulkan bukti-bukti dari pembelajaran siswa.

e. Analyze Evidence of Learning: tim mendiskusikan hasil dan menilai kemajuan dalam pencapaian tujuan belajar siswa

f. Repeat the Process: kelompok merevisi pembelajaran, mengulang tahapan- tahapan mulai dari tahapan ke-2 sampai dengan tahapan ke-5 sebagaimana dikemukakan di atas, dan tim melakukan sharing atas temuantemuan yang ada.

\section{METODE PENELITIAN}

Subjek penelitian pada penelitian ini adalah guru kelas di SD Negri 2 Penganten.

$$
\text { Jadwal kegiatan Penelitian }
$$
Tindakan Sekolah (PTS) ini direncanakan dan dilaksanakan sebagaimana pada tabel di bawah ini

\section{Tabel 1. Waktu Penelitian Tindakan Sekolah}

\begin{tabular}{|l|l|l|l|}
\hline No. & \multicolumn{1}{|c|}{ Tanggal } & Siklus & Tindakan \\
\hline 1 & 20 Januari 2018 & 1 & $\begin{array}{l}\text { Pengamatan dan penilaian RPP guru-guru dan } \\
\text { Mengadakan Pembinaan Melalui Metode Lesson Study. }\end{array}$ \\
\hline 2 & 27 Januari 2018 & 1 & Melakukan Supervisi Klinis \\
\hline 3 & 3 Februari 2018 & 2 & $\begin{array}{l}\text { Pengamatan dan penilaian RPP guru-guru dan } \\
\text { Mengadakan Pembinaan Melalui Metode Lesson Study. }\end{array}$ \\
\hline 4 & 10 Februari 2018 & 2 & Supervisi akademik \\
\hline
\end{tabular}




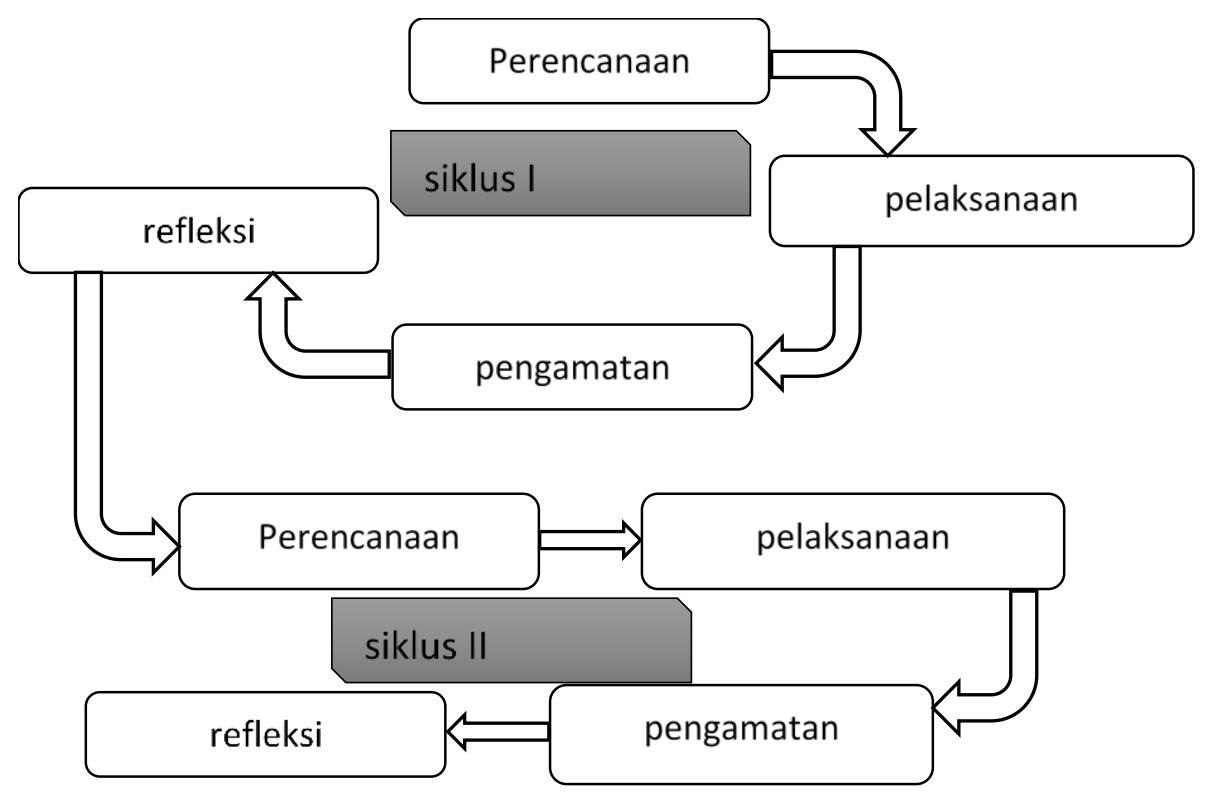

Gambar 3.1. Langkah-langkah PTS (Direktorat Tendik, 2008)

Penelitian ini dilaksanakan dengan menggunakan disain penelitian tindakan (action research) yang dirancang melalui dua siklus melalui prosedur: (1) perencanaan (planning), (2) pelaksanaan tindakan (action), (3) pengamatan (observation), (4) refleksi (reflecsion) dalam tiap-tiap siklus.

Teknik pengumpulan data melalui observasi atau pengamatan, wawancara, dan studi dokumentasi instrumen pengumpul data meliputi :

1. Instrumen penilaian kinerja guru dalam merencakan pembelajaran

2. Instrumen penilaian kinerja guru dalam melaksanakan proses pembelajaran dan penilaian hasil belajar
3. Instrumen penialain terhadap abilitas guru dalam pembelajaran

Setelah seluruh data yang diperlukan maka langkah selanjutnya adalah mengolah data dan menganalisis data yang cara-caranya sebagai berikut:

1. Deduksi yaitu upaya memperoleh data yang bersifat khusus melalui penalaran dan penganalisisan datadata yang bersifat umum.

2. Induksi upaya memperoleh data-data yang bersifat umum melalui penalaran dan penganalisasian terhadap data yang bersifat khusus.

3. Menyandingkan beberapa keterangan atau data yang diperoleh untuk mendapatkan argumentasi yang lebih serta mampu memberikan kejelasan 
yang layak untuk dijadikan pegangan dalam penelitian.

\section{HASIL DAN PEMBAHASAN}

Kondisi awal Guru sekolah dasar di SD Negeri 2 Penganten UPTD Pendidikan Kecamatan Klambu, Kabupaten Grobogan sebelum dilakukan tindakan pada siklus I, didapatkan tingkat kinerja guru. hasil kinerja Guru sekolah dasar SD Negeri 2 Penganten memiliki skor rata- rata $38,375 \%$, yang meliputi rata- rata komponen perencanaan pembelajaran sebesar 39,5\% dan ratarata komponen pelaksanaan pembelajaran $37,5 \%$ serta rata- rata komponen abilitas guru $38,125 \%$. Kategori persentase kinerja guru tersebut termasuk pada kategori yang rendah, sebagaimana tabel berikut :

Tabel 2. Persentase Kategori Kinerja Guru Sebelum Tindakan

\begin{tabular}{|c|c|c|c|}
\hline No & Persentase & Kategori & $\begin{array}{c}\text { Hasil } \\
\text { Kinerja } \\
\text { Guru }\end{array}$ \\
\hline 1 & $0 \%-20 \%$ & $\begin{array}{c}\text { Sangat } \\
\text { Rendah }\end{array}$ & \\
\hline 2 & $21 \%-40 \%$ & Rendah & $\mathbf{3 8 , 3 7 5 \%}$ \\
\hline 3 & $\mathbf{4 1 \% - 6 0 \%}$ & Sedang & \\
\hline 4 & $61 \%-80 \%$ & Tinggi & \\
\hline 5 & $81 \%-100$ & $\begin{array}{c}\text { Sangat } \\
\text { Tinggi }\end{array}$ & \\
\hline
\end{tabular}

Berdasarkan data di atas menunjukkan bahwa kinerja guru pada komponen perencanaan pembelajaran, yang paling rendah adalah dalam merencanakan pembelajaran yaitu hanya
$32 \%$ dan paling tinggi $44 \%$, dan pada komponen pelaksanaan pembelajaran adalah dalam melaksanakan tindak lanjut/follow up yang hanya mencapai 35 $\%$ dan paling tinggi $40 \%$, serta pada komponen abilitas guru adalah keterampilan memberikan variasi stimulus pembelajaran yaitu $30 \%$ dan paling tinggi $45 \%$. Untuk data lebih lengkap bisa dilihat di lampiran hasil penilaian kinerja guru pra siklus. Dari hasil pra siklus tersebut, perlu dilakukan tindakan siklus I. bahwa kinerja Guru sekolah dasar SD Negeri 2 Penganten memiliki rata- rata skor $84,583 \%$, yang meliputi rata- rata komponen perencanaan pembelajaran sebesar $82,5 \%$ dan ratarata komponen pelaksanaan pembelajaran $83,75 \%$ serta rata- rata komponen abilitas guru 87,5 \% Kategori persentase kinerja guru tersebut termasuk pada kategori yang sangat tinggi, perhatikan tabel berikut.

Tabel 3. Persentase Kategori Kinerja Guru Hasil Refleksi Siklus II

\begin{tabular}{|c|c|c|c|}
\hline No & Persentase & Kategori & $\begin{array}{c}\text { Hasil } \\
\text { Kinerja } \\
\text { Guru }\end{array}$ \\
\hline 1 & $0 \%-20 \%$ & $\begin{array}{c}\text { Sangat } \\
\text { Rendah }\end{array}$ & \\
\hline 2 & $21 \%-40 \%$ & Rendah & \\
\hline 3 & $41 \%-60 \%$ & Sedang & \\
\hline 4 & $\mathbf{6 1 \% - 8 0 \%}$ & Tinggi & \\
\hline 5 & $81 \%-100$ & $\begin{array}{c}\text { Sangat } \\
\text { Tinggi }\end{array}$ & $84,583 \%$ \\
\hline
\end{tabular}


Hasil tindakan pada siklus II menunjukkan bahwa kinerja guru pada komponen perencanaan pembelajaran, yang paling rendah adalah $72 \%$ dan yang paling tinggi $96 \%$, dan pada komponen pelaksanaan pembelajaran yang paling rendah mencapai 77,5 \% dan yang paling tinggi $97,5 \%$, sedangkan pada komponen abilitas guru adalah keterampilan memberikan penguatan yaitu mencapai $80 \%$ dan yang paling tinggi $95 \%$.
Peningkatan kinerja guru secara keseluruhan adalah dari awal sebesar $38,375 \%$ (kategori rendah), setelah tindakan siklus I menjadi 60\% (kategori sedang), dan setelah tindakan siklus II meningkat lagi menjadi 84,583 \% (kategori sangat tinggi) untuk lebih jelasnya dapat dilihat pada grafik berikut

\section{Tabel 4 Persentase Kategori Kinerja Guru Awal, Hasil Siklus I dan Siklus II}

\begin{tabular}{|c|c|c|c|c|c|}
\hline \multirow{2}{*}{ No } & \multirow{2}{*}{ Persentase } & \multicolumn{3}{|c|}{ \% Kinerja Guru } & \multirow{2}{*}{ Kategori } \\
\cline { 3 - 5 } & & Awal & Siklus I & Siklus II & \\
\hline 1 & $0 \%-20 \%$ & & & & Sangat Rendah \\
\hline 2 & $21 \%-40 \%$ & & & & Rendah \\
\hline 3 & $41 \%-60 \%$ & $\mathbf{5 8 , 3 \%}$ & & & Sedang \\
\hline 4 & $\mathbf{6 1 \% - 8 0 \%}$ & & $\mathbf{6 0 \%}$ & & Tinggi \\
\hline 5 & $81 \%-100 \%$ & & & $\mathbf{8 4 , 5 8 3 \%}$ & Sangat Tinggi \\
\hline
\end{tabular}

Kondisi awal sebelum diterapkan metode Lesson Study secara rutin sebelum guru melakukan tugas mengajar menunjukkan:

1. Kurangnya kesadaran dan tanggung jawab guru akan tugas pokok dan fungsi yang dibebankan oleh pemerintah.

2. Kurangnya perencanaan yang matang dalam melaksanakan tugas dan belum siapnya guru untuk mengadakan perubahan kearah yang lebih maju sesuai dengan perkembangan dunia pendidikan.

3. Kurangnya pemahaman guru akan tugasnya sebagai agen pembelajaran.

4. Belum terbentuknya disiplin sekolah dan iklim budaya kerja sekolah yang mengacu pada peningkatan mutu pembelajaran.

Pemahaman guru terhadap tugas sebelum diterapkannya pendekatan tersebut adalah dalam melaksanakan tugasnya hanya mengandalkan persiapan seadanya bahkan kadang sama sekali tidak 
ada persiapan. Hal ini terjadi karena fungsi kontrol sebagai salah satu tugas kepala sekolah tidak berjalan sebagaimana mestinya. Disamping itu seolah-olah guru hanya sekedar melaksanakan tugas tanpa ada perancanaan yang matang dan tidak berpikir bagaimana hasil akhir setelah melaksanakan tugas mengajar. Dapat dibayangkan jika seorang kepala sekolah tidak mempunyai kemampuan untuk mengatur, memimpin, mengelola atau mengadministrasikan sumber daya meliputi perencanaan, pelaksanaan, pengawasan, dan pembinaan terhadap guru-guru sebagai bawahannya. Teknik Lesson Study dikemas agar menarik, memukau dan apa yang kepala sekolah sampaikan langsung masuk dan dapat diaplikasikan dalam kegiatan pembelajaran oleh guru-guru.

Pertama kali yang harus disadari adalah apa yang akan kita sampaikan. Kepala sekolah harus memahami visi sekolah. Visi sekolah akan menurunkan Misi yang sekolah buat dalam waktu yang pendek. Misi yang sekolah buat inilah yang akan menurunkan culture kerja. Culture kerja inilah yang kemudian akan memunculkan Motivasi kerja. Jadi dengan memahami Visi, kepala sekolah akan dapat menciptakan budaya kerja dalam tim sekolah dan sekaligus memunculkan motivasi personil.

Yang kedua, yang harus kepala sekolah sadari bahwa pada saat teknik Lesson Study dimulai, kepala sekolah harus menyadari secara sepenuhnya bahwa teknik ini adalah teknik yang berkesinambungan, yang akan membutuhkan waktu untuk bisa beradaptasi dengan teknik baru, maka diperlukan keuletan dan kesabaran dalam mengolah manajemen di sekolah.

\section{PENUTUP}

\section{Simpulan}

Berdasarkan pembahasan hasil penelitian yang telah dilakukan dalam bab sebelumnya melalui "Upaya Peningkatan Kinerja Guru Melalui Teknik Lesson Study Secara Kolaboratif dan Rutin Di SD Negeri 2 Penganten" dapat ditarik kesimpulan, sebagai berikut:

1. Pelaksanaan program yang rutin dan berkesinambungan merupakan kunci keberhasilan dalam melaksanakan tugas sebagai kepala sekolah dalam meningkatkan mutu pembelajaran di kelas.

2. Pada "Upaya Peningkatan Kinerja Guru Melalui Teknik Lesson Study Secara Kolaboratif dan Rutin Di SD Negeri 2 Penganten" ternyata mampu membentuk tenaga pendidik 
yang produktif/ profesional dan mampu meningkatkan mutu pembelajaran.

3. Dengan adanya terobosan dan inovasi melalui pendekatan "Upaya Peningkatan Kinerja Guru Melalui Teknik Lesson Study Secara Kolaboratif dan Rutin Di SD Negeri 2 Penganten" ternyata ada pengaruh yang besar terhadap hasil belajar siswa.

\section{Saran}

Berdasarkan kesimpulan di atas, guru dituntut untuk melaksanakan beberapa hal dalam meningkatkan kualitas pembelajaran, khususnya dalam meningkatan penguasaan materi pelajaran dan keaktifan siswa dalam belajar. Adapun hal-hal yang harus dilakukan guru diantaranya :

1. Menentukan tujuan pembelajaran (lesson) satuan (unit) pelajaran, dan mata pelajaran yang efektif.

2. Mengkaji dan meningkatkan pelajaran yang bermanfaat bagi siswa.
3. Memperdalam pengetahuan tentang mata pelajaran yang disajikan para guru.

4. Menentukan tujuan jangka panjang yang akan dicapai para siswa.

5. Menentukan pelajaran secara kolaboratif.

6. Mengkaji secara teliti belajar dan perilaku siswa.

7. Mengembangkan pengetahuan pembelajaran yang dapat diandalkan.

8. Melakukan refleksi terhadap pengajaran yang dilaksanakannya berdasarkan pandangan siswa dan koleganya.

Disamping itu, pengalaman dalam pelaksanaan penelitian tindakan sekolah (PTS) perlu adanya kelompok kerja antara guru, untuk saling tukar pikiran dan pengalaman, serta saling membantu dalam memecahkan masalah yang dihadapi sehari-hari dalam tugas yang diemban dalam mengaja

\section{DAFTAR PUSTAKA}

Hendayana S.. 2006. Lesson Study Suatu Strategi untuk Meningkatkan Keprofesionalan Guru (Pengalaman JUSTEP-JICA). Bandung: UPI Press. 
Parmin dan Siti Aminah. 2008. Menerapkan Lesson Study Dalam Pembelajaran di MI Madariful Huda Pati. Laporan Penelitian Dosen Muda. FMIPA: Universitas Negeri Semarang.

Widhiartha, Putu Ashintya. Dwi Sudarmanto. Nining Ratnasingsih. 2008. Lesson Study Sebuah Upaya Peningkatan Mutu Pendidik Pendidikan Non Formal. Surabaya: Prima Printing.

Yusak, Muchlas. 2008. Lesson Study: Pengembangan Profesi Guru Secara Berkelanjutan Berbasis Sekolah. Semarang: LPMP Jawa Tengah.

http://www.slideshare.net/aminhers/lesson-study, Lesson Study-resentation Transcript, 2010 